\title{
A nephrologist should be consulted in all cases of acute kidney injury in the ICU: We are not sure
}

Miet Schetz ${ }^{1 *}$ [D and Matthieu Legrand ${ }^{2,3,4}$

@ 2017 Springer-Verlag Berlin Heidelberg and ESICM

\section{Introduction}

The development of a consensus definition of acute kidney injury (AKI) has revealed the scope of this syndrome, both inside and outside the ICU. It is now increasingly clear that AKI affects more than $50 \%$ of ICU patients [1] and that it is associated with poor outcomes both shortterm and long-term [2]. Efforts to change that grim prognosis are therefore of utmost importance and should concentrate on every phase of the disease process and involve all caregivers that may contribute to improved outcomes. Opinions on whether or not to consult a nephrologist for every patient with AKI in the ICU may differ $[3,4]$. The respective arguments concentrate on the specific role of the intensivist, the different organizational models of the ICU, the scale and diversity of the problem, and the post-discharge "legacy" of AKI [3, 4].

\section{The divergent training and knowledge of intensivists and nephrologists}

Intensivists are dedicated to the treatment of patients with severe life-threatening conditions requiring vital organ support and/or invasive monitoring. ICU training programs involve the acquisition of knowledge and skills that are specific to critically ill patients and involve all aspects of the care of the critically ill [5]. Intensivists do not consult cardiologists for every low cardiac output or pulmonologist for every hypoxia. However, the intensivist should have knowledge of renal (patho)physiology and

\footnotetext{
*Correspondence: marie.schetz@uzleuven.be

${ }^{1}$ Division of Cellular and Molecular Medicine, Clinical Department and Laboratory of Intensive Care Medicine, KU Leuven University, Herestraat 49, 3000 Louvain, Belgium

Full author information is available at the end of the article
}

For contrasting viewpoints, please go to doi:10.1007/s00134-017-4712-5 and doi:10.1007/s00134-017-4790-4. recognize and manage the patient with or at risk of AKI. In "closed" ICUs where intensivists have final responsibility for all aspects of patient care, they often also initiate and manage renal replacement therapy (RRT) [5]. The "closed" organization, however, does not exclude interactions with other specialties for the management of difficult cases. In addition, many ICU teams are composed of physicians with multidisciplinary backgrounds. The many "open" ICUs in the USA are at the other end of the spectrum, with the referring physician maintaining responsibility and organs specialists being involved in the form of daily rounds or on-call consultation. It is evident that AKI is part of nephrology training. However, in daily practice nephrologists spend a great part of their clinical time managing renal problems in systemic diseases (e.g., glomerulonephritis), chronic kidney disease (CKD), chronic dialysis, and kidney transplantation. A member of the ICU team with nephrology training probably represents the ideal "manager" for AKI patients. Training and skills of ICU nurses as well as personal relationships, local politics, and financial issues may also play an important role.

\section{Why every intensivist should be able to manage the early phase of AKI}

Several features of AKI in the ICU are incompatible with routine management by consultant nephrologists (Table 1).

1. AKI develops in more than $50 \%$ of ICU patients. A nephrology consultation for every episode of AKI would require an enormous expansion of the nephrology community.

2. Severe AKI nowadays mainly occurs in the ICU setting and is part of multiple organ failure. This type of AKI may substantially differ from the AKI in ward 
Table 1 Role of the nephrologist in the ICU

\begin{tabular}{llc}
\hline Improbable in most ICUs & Desirable in most ICUs & Mandatory in all ICUs \\
\hline $\begin{array}{l}\text { Prevention of AKI } \\
\text { Initial diagnostic approach to AKI }\end{array}$ & \\
Management of early AKI & Diagnostic approach and treatment of specific causes \\
Indication for RRT & Provision of intermittent hemodialysis \\
Choice of RRT modality & Translation of knowledge from the CKD population \\
Prescription of fluid management & & Post-discharge nephrological follow-up \\
\hline
\end{tabular}

patients. Furthermore, diagnostic work-up as taught to nephrology residents may not be applicable to ICU patients. As an example, the accuracy of the classical urinary indices for the differential diagnosis between prerenal and renal causes is disappointing in ICU patients [6].

3. Prevention is the best approach to AKI and requires good basic intensive care including infection prevention, early antibiotics when appropriate, protective mechanical ventilation, minimal sedation, hemodynamic management, etc. In addition, the holistic management of the ICU patient may require prioritizing treatments that may be life-saving but harm the kidney (e.g., administration of aminoglycosides in septic shock with multidrug-resistant organisms, establishing a vital diagnosis with contrast administration, etc.). Intensivists are most experienced in assessing this benefit-to-risk ratio.

4. In the absence of classical indications, the decision to start RRT and the choice of modality are often more dependent on the underlying pathology than on the actual level of kidney function [7]. Once RRT is started, the management of fluid balance is part of the global management of the patient, should constantly be adapted to the actual situation of the patient, and cannot be directed by an external consultant.

\section{What should be the role of the nephrologist in the ICU?}

The foregoing argumentation certainly does not exclude an important role for nephrologists in the management of ICU patients with AKI. There are many areas where nephrology input is desirable or even mandatory (Table 1).

1. The diagnostic approach in patients where the etiology of AKI is not directly evident or when routine screening yields results that raise suspicion of a specific renal problem such as glomerulonephritis undoubtedly requires the input of a nephrologist to avoid delaying potentially life- or kidney-saving treatments. Rare and complicated electrolyte disorders may also require nephrology consultation.

2. Transfer of knowledge between the ICU and nephrology, e.g., during daily rounds, will undoubtedly improve the quality of care. For instance, nephrologists may draw attention to the long-term consequences of dialysis catheters in the subclavian vein [8], although ICU studies suggest this vein as the preferential site for catheter placement [9]. Nephrologists may suggest modifications to the intermittent dialysis procedure that promote hemodynamic stability, e.g., blood volume monitoring or sodium profiling $[10,11]$. In this way, nephrologists could assist in the development of procedures and protocols for RRT and in quality improvement programs.

3. The most important role for the nephrologist, however, is in the follow-up of AKI patients after ICU and hospital discharge. In many AKI patients, kidney function will not return to baseline and even after complete recovery the risk of progression to $\mathrm{CKD}$ is increased [12]. Involving the nephrologist before the patient is discharged to the ward will avoid that many are "lost to follow-up" resulting in an important care gap. This post-ICU nephrological follow-up, especially after severe AKI, should include regular assessment of kidney function and institution of the appropriate therapy to prevent further progression to CKD [13]. Such an approach may improve long-term outcomes [14] but is currently neglected [15].

\section{Conclusion}

AKI is a common syndrome in the ICU. Its development/ deterioration can be prevented by the interventions of skilled intensivists. The involvement of nephrologists should minimally include the diagnosis of difficult and rare kidney diseases and the long-term follow-up of AKI patients after discharge. Knowledge-sharing and cooperation between intensivists and nephrologists have great potential to further improve the outcome of AKI patients. 


\section{Author details}

${ }^{1}$ Division of Cellular and Molecular Medicine, Clinical Department and Laboratory of Intensive Care Medicine, KU Leuven University, Herestraat 49, 3000 Louvain, Belgium. ${ }^{2}$ Department of Anesthesiology and Critical Care and Burn Unit, AP-HP, St-Louis Hospital, Paris, France. ${ }^{3}$ INSERM UMR-S942, Institut National de la Santé et de la Recherche Médicale (INSERM), Lariboisière Hospital, Paris, France. ${ }^{4}$ Univ Paris Diderot, 75475 Paris, France.

\section{Compliance with ethical standards}

This article does not contain any studies with human participants or animals performed by any of the authors.

\section{Conflicts of interest}

The authors declare that they have no conflict of interest in relation to this manuscript.

Received: 10 January 2017 Accepted: 31 March 2017 Published online: 22 May 2017

\section{References}

1. Hoste EA, Bagshaw SM, Bellomo R, Cely CM, Colman R, Cruz DN, Edipidis K, Forni LG, Gomersall CD, Govil D, Honoré PM, Joannes-Boyau O, Joannidis M, Korhonen AM, Lavrentieva A, Mehta RL, Palevsky P, Roessler E, Ronco C, Uchino S, Vazquez JA, Vidal Andrade E, Webb S, Kellum JA (2015) Epidemiology of acute kidney injury in critically ill patients: the multinational AKI-EPI study. Intensive Care Med 41:1411-1423

2. Doyle JF, Forni LG (2016) Acute kidney injury: short-term and long-term effects. Crit Care 20(1):188

3. Kellum JE, Hoste EAJ (2017) A nephrologist should be consulting in all cases of acute kidney injury in the ICU: no. Intensive Care Med. doi:10.1007/s00134-017-4712-5

4. Flaaten H, Darmon M (2017) A nephrologist should be consulting in all cases of acute kidney injury in the ICU: yes. Intensive Care Med. doi:10.1007/s00134-017-4790-4
5. CoBaTrICE Collaboration, Bion JF, Barrett H (2006) Development of core competencies for an international training programme in intensive care medicine. Intensive Care Med 32:1371-1383

6. Legrand M, Le Cam B, Perbet S, Roger C, Darmon M, Guerci P, Ferry A, Maurel V, Soussi S, Constantin JM, Gayat E, Lefrant JY, Leone M, support of the AZUREA network (2016) Urine sodium concentration to predict fluid responsiveness in oliguric ICU patients: a prospective multicenter observational study. Crit Care 20:165

7. Schetz M, Forni LG, Joannidis M (2016) Does this patient with AKI need RRT? Intensive Care Med 42:1155-1158

8. Wyatt CM, Vassalotti JA (2016) We still go for the jugular: implications of the 3SITES central venous catheter study for nephrology. Kidney Int 89:522-524

9. Parienti JJ, Mongardon N, Mégarbane B, Mira JP, Kalfon P, Gros A, Marqué S, Thuong M, Pottier V, Ramakers M, Savary B, Seguin A, Valette X, Terzi N, Sauneuf B, Cattoir V, Mermel LA, du Cheyron D, 3SITES Study Group (2015) Intravascular complications of central venous catheterization by insertion site. N Engl J Med 373:1220-1229

10. Dasselaar JJ (2007) Relative blood volume based biofeedback during haemodialysis. J Ren Care 33:59-65

11. Dunne N (2016) A meta-analysis of sodium profiling techniques and the impact on intradialytic hypotension. Hemodial Int. doi:10.1111/hdi.12488

12. Bucaloiu ID, Kirchner HL, Norfolk ER, Hartle JE 2nd, Perkins RM (2012) Increased risk of death and de novo chronic kidney disease following reversible acute kidney injury. Kidney Int 81:477-485

13. Levin A, Stevens PE (2011) Early detection of CKD: the benefits, limitations and effects on prognosis. Nat Rev Nephrol. 7:446-457

14. Harel Z, Wald R, Bargman JM, Mamdani M, Etchells E, Garg AX, Ray JG, Luo J, Li P, Quinn RR, Forster A, Perl J, Bell CM (2013) Nephrologist follow-up improves all-cause mortality of severe acute kidney injury survivors. Kidney Int 83:901-908

15. Kirwan CJ, Blunden MJ, Dobbie H, James A, Nedungadi A, Prowle JR (2015) Critically ill patients requiring acute renal replacement therapy are at an increased risk of long-term renal dysfunction, but barely receive nephrology follow-up. Nephron 129:164-170 